\title{
THE DISTRIBUTION AND WASTE DISPOSAL PROBLEM
}

\section{Jacqueline M. Bloemhof-Ruwaard , Landbouw Universiteit Wageningen, NL Marc Salomon, Erasmus Universiteit Rotterdam, NL Luk N. Van Wassenhove, INSEAD Fontainebleau Cedex, France}

We study the problem of the simultaneous design of a distribution network with plants and waste disposal units, and the coordination of product flows and waste flows within this network. Problem objective is to minimize total relevant costs, consiting of fixed costs for opening plants or waste disposal units, and variable costs, related to product and waste flows. The problem is complicated by the presence of

(i) service requirements (i.e. production must cover total demand) and

(ii) waste - that arises from production - must be disposed at waste disposal units.

We consider the uncapacitated version of the problem, as well as its capacitated version, in which capacity constraints exist on plants and waste disposal units.

We discuss alternative mathematical model formulations for the two-level distribution and waste disposal problem with and without capacity constraints. Also, lower bounding and upper bounding procedures are analysed with respect to their quality. Finally, the results of a computational study are reported.

Keywords:

capacitated facility location, mixed integer programming, relaxations, heuristics 